\title{
Assessment of Capitalization as a Management Tool of Economic Development of a Region
}

\author{
Julia V. Lyshchikova \\ Yevgenia V. Nikulina \\ Anna V. Orlova \\ Irina V. Chistnikova \\ Belgorod State National Research University, Russian Federation \\ Email: lyshchikova@bsu.edu.ru
}

\section{Doi:10.5901/mjss.2015.v6n3s5p93}

\begin{abstract}
The article suggests the authors' definition of capitalization of regional economy as a process of effective business usage, increase of revenues and values of complex capital assets of regional economic agents. The functions of capitalization are systematized and peculiarities of their implementation at the regional level are revealed. The authors define and structure the objects of capitalization of regional economy. The author's methodology and tools of assessment of capitalization of regional economic potential based on the income approach with the usage of integral indicators are developed. The results of the investigation are presented as a map of development and capitalization of regional economic potential of the regions of Central Black Earth economic region. The conclusions justify the set of measures to increase the capitalization of regional economic potential differentiated in key areas.
\end{abstract}

Keywords: regional economy, economic potential, assessment methodology, map of capitalization, set of measures

\section{Introduction}

Regional economies are characterized by the integrity of the reproductive process, caused by the presence of a homogeneous set of factors of production, and have the potential for development of economic entities located on its territories. At the same time the restriction of territorial formation by administrative boundaries, the existing industry specialization of economic agents often lead to the fact that a significant part of regional economic potential is not used adequately. In this connection, it is necessary to create conditions for the growth of the involvement of regional economic potential into the economic turnover to increase the level of capitalization of regional formation.

Undoubtedly, Russia's WTO accession also actualizes the problem of capitalization of Russian regions. Low capitalization of regional capital may lead to increasing dependence of the whole national economy from world markets conjuncture. It is required to match a process of economic evolution, including the value of national and regional capital to enter into the world economic system on acceptable terms, to provide for the positioning of regions in global markets (Lyshchikova, 2013).

The comparison of the level of capitalization of regions in the dynamics allows to characterize the uniformity of development of the territory, the efficiency of economic institutions, and the impact of federal and municipal programs to stimulate growth, the adequacy of economic policy and to define directions of formation of an effective model of regional economic development (Gavkalova \& Barka Zine, 2012; Goryachuk et al., 2012; Nikulina et al., 2013).

In this situation, the study of economic content of the problem of increasing of the capitalization of economic potential of regional economy, an objective analysis of fundamental factors affecting the change in the value of regional capital, setting priorities for the long-term strategy to increase the capitalization of regional economy are of a great scientific interest. 


\section{Literature Review}

\subsection{Definition and levels of capitalization}

In a market economy the capitalization process is considered as an ambivalent phenomenon: on the one hand, it is the accumulation of real capital, on the other hand, it is the increase in value of functioning capital in the stock market (Brasington, 2002; Malova, 2007; Toly, 2004).

In considering the various forms of capitalization we should pay attention to the classification based on the level of aggregation: the micro-level (capitalization of the company or of the market), the meso-level (capitalization of the region), and the macro-level (the capitalization of the country) (Dedkova, 2008; Malova, 2007). In our opinion, it is also necessary to consider the context of mega-level of capitalization of the world economy, as in the context of growing economic integration and globalization the scale of cross-border redistribution and use of economic resources are increasing; thereby uncapitalised national assets become the object of exploitation and appropriation for the subjects of world markets.

Based on the analysis of works of domestic and foreign researchers of capitalization, including the regional level (Brasington, 2002; Darmilova, 2007; Dedkova, 2008; Malova, 2007; Toly, 2004), we propose to define the capitalization of regional economy as a process of involving into economic circulation, effective using and increasing the value of complex of capital assets of regional economic agents, increasing revenues from their operation to realize the advantages of the region at the national and international level.

\subsection{Functions of capitalization of regional economy}

The economic essence of regional capitalization process is manifested by its functions (Darmilova, 2007; Dedkova, 2008; Malova, 2007). Distribution function of capitalization process promotes redistribution of capital between sectors and economic actors in the region, to equalize the marginal productivity of capital in regional economy. This trend is the stronger, the more advanced the elements of institutional infrastructure of the region, which is the main factor of effective implementation of the function.

Reproduction function of capitalization supports a continuous process of circulation and accumulation of capital, both at the national and regional level. The implementation of this function regulates the rates, proportions, sectoral and territorial structure of regional economy.

Strategic function of capitalization process consists in the formation of resources, ensuring the strategic development of the region in the long term. The region provides an implementation of this function of capitalization due to strategic development of its areas, based not only on the creation of new enterprises, but also the increasing of the value of the capital by the conversion of land assets into the capital, improving the quality of human or the value of intellectual capital concentrated in the region.

Innovative function of capitalization is the financing of innovations by increasing the value of intangible and current assets as well as human capital (Nikulina et al., 2012). Due to this function, the process of capitalization of innovation creates an additional value due to the innovation involving smaller amounts of physical capital. It is replaced by the capital in the form of rights to finance, technology, information, and other intellectual resources.

- Information function of market capitalization of region is formed through the capital ratios that reflect the current and future state of a particular region.

- Forecasting function of the capitalization of region serves as an indicator of the future status of the region through the assessment of its potential.

- Mobilization function of the capitalization of region provides concentration of investors' funds for regional development in the context of the modernization and expansion of production.

The list of functions of capitalization of regional economy can be supplemented by investment function because capitalization, as a value which reflects the potential of the region can be regarded as an indicator of investment attractiveness.

It is also reasonable to allocate marketing function of capitalization of regional economy, defined as a market attractiveness of the region in the global market of various goods and services.

\subsection{Objects of capitalization of regional economy and principles of their interrelation}

It is necessary to define the objects of capitalization in the region to disclose its nature. The objects of capitalization of 
regional economy are the long-term assets (capital) of regional economic agents represented by the property of the households, companies and the region, including both resources in circulation, and not exploited (Ovchinnikova \& Lyshchikova, 2011).

The study found that territorial resources, acting in the reproduction process in the form of income-generating assets together form regional economic potential, which enable to formulate a set of determinate concepts 'Potential Resources - Assets' and to prove the decisive role of economic potential of the region in securing and improving the level of capitalization of regional economy (Darmilova, 2007).

This conclusion is based on the principles of the system, reproduction and resource approach to the study of capitalization of regional economic systems, in contrast to the prevailing understanding of the region as a "quasicorporation". Since territorial assets are closely linked with each other and largely determine the existing structure and specialization of regional economy, their complexity should be identified as an important feature to exploit synergies in the task of territorial capitalization.

\section{Research Methodology}

The results of the analysis of the methodologies for assessment of capitalization of the regional economy (Darmilova, 2007; Molchan, 2011; Pogodzinski \& Sjoquist, 1993; Tsybulsky \& Silifonkina, 2010) have shown that currently there is no single universally accepted method for determining its level, which allows offering the assessment methodology, which includes theoretical, analytical and operational stages.

During the first stage of the proposed methodology Russian and foreign scientists approaches and methods of the assessment of the level of capitalization of regional economy were analyzed. Capitalization method (as one of two basic methods in the income approach) is chosen, because it is used, if revenue streams are stable for a long period of time, represent a significant positive value and increase in sustainable, moderate pace that is fully consistent with the characteristics of regional income.

In calculating the level of capitalization of regional economy gross regional product (GRP) per capita is used as a generalizing indicator of regional income because it represents the amount of value added produced on the basis of regional assets. As an indicator of potential profitability in relation to the territorial subject we propose an integrated indicator of the level of development of economic potential of the region, which allows estimating the potential value and attractiveness of the area for external entities (regions, countries, companies, etc.) and reflecting the perspectives of possible profitability of regional assets.

As a result of the analysis of the structure of capitalized assets of territorial entity the system of particular statistic indicators $x_{i}$ which characterize 6 selected regional subpotentials is formed (Table 1).

Table 1. The system of particular and aggregate indicators of the level of development of economic potential of the region

\begin{tabular}{|c|c|}
\hline Regional subpotential & Particular statistic indicators, $\mathbf{x}_{\mathbf{i}}$ \\
\hline \multirow{3}{*}{$\begin{array}{l}\text { 1. Natural resource } \\
\text { subpotential }\end{array}$} & 1. The value of mineral resources in the region per capita (thousand rubles) \\
\hline & 2. Sown area of all crops per capita (thousand hectares) \\
\hline & 3. The percentage of forest land (\%) \\
\hline \multirow[t]{3}{*}{ 2. Labour subpotential } & 1. The level of economic activity of the population (\%) \\
\hline & 2. The share of skilled labour employed in the economy of the region in total employment (\%) \\
\hline & 3. The number of students of educational institutions of higher education per 10,000 population (persons) \\
\hline \multirow{2}{*}{$\begin{array}{l}\text { 3. Production } \\
\text { subpotential }\end{array}$} & 1. The value of fixed assets per capita (thousand rubles) \\
\hline & 2. Gross fixed capital per capita (million rubles) \\
\hline \multirow{4}{*}{ 4. Innovative subpotential } & 1. Innovation activity of organizations (\%) \\
\hline & 2. The share of innovative goods, works and services in the total volume of goods, works, services (\%) \\
\hline & 3. The share of employees involved in scientific research and development, in total employment (\%) \\
\hline & 4. The number of patents for inventions and utility models on 10,000 population (units) \\
\hline \multirow{6}{*}{$\begin{array}{l}\text { 5. Infrastructure } \\
\text { subpotential }\end{array}$} & 1. The number of enterprises and organizations of the sphere of credit and insurance services per capita (units) \\
\hline & 2. The number of enterprises and organizations of the sphere of operations with real estate, rent and services per capita (units) \\
\hline & 3. The number of enterprises and organizations of transport and communications per capita (units) \\
\hline & 4. The density of railway lines for general use ( $\mathrm{km}$ of track per 10,000 square $\mathrm{km}$ of territory) \\
\hline & 5. The density of public roads paved ( $\mathrm{km}$ of roads per 10,000 square $\mathrm{km}$ of territory) \\
\hline & 6. Capacity of power plants (million kWh per capita) \\
\hline \multirow{3}{*}{ 6. Financial subpotential } & 1. The revenues of consolidated budget of the region per capita (million rubles) \\
\hline & 2. Deposits of legal entities in rubles and foreign currency raised by credit institutions per capita (million rubles) \\
\hline & 3. Deposits of individuals in roubles and foreign currency attracted by credit institutions per capita (million rubles) \\
\hline
\end{tabular}


The methods for normalization of particular statistic indicators $x_{i}$ into basic indicators $f_{i}$, for aggregation of the results into generalized indicators $\mathrm{F}_{\mathrm{i}}$, for calculation of integral indicator of the level of development of economic potential of the region $\mathrm{I}_{\mathrm{i}}$ and the capitalization of regional economy $\mathrm{LC}_{\mathbf{i}}$ are defined in Table 2.

Table 2. Assessment tools of the level of capitalization of regional economy

\begin{tabular}{|c|c|}
\hline Formula & Designations \\
\hline \multicolumn{2}{|c|}{ 1. Basic indicators of the $1^{\text {st }}$ level, $\mathrm{fi}_{\mathrm{i}}$} \\
\hline$f_{i}=\frac{x_{i}}{x_{i r u s}}$ & $\begin{array}{l}x_{i} \text { - the value of regional statistical indicator; } \\
x_{i} \text { rus - the value of national average statistical indicator. }\end{array}$ \\
\hline \multicolumn{2}{|c|}{ 2. Aggregated indicators of the $2^{\text {nd }}$ level, $F_{i j}$} \\
\hline$F_{i j}=\sqrt[k]{\prod_{n=1}^{k} f_{i n}}$ & $\begin{array}{l}\mathrm{f}_{\mathrm{i}}-\text { the values of basic indicators of the } 1^{\text {st }} \text { level; } \\
\mathrm{k} \text { - the number of basic indicators of the } 1^{\text {st }} \text { level for corresponding generalized indicator. }\end{array}$ \\
\hline \multicolumn{2}{|c|}{ 3. Rating number of the level of development of economic potential, $\mathrm{R}_{\mathrm{i}}$} \\
\hline$R_{i}=\sqrt{\sum_{j=1}^{n} F_{i j}^{2}}$ & $\begin{array}{l}\mathrm{F}_{\mathrm{ij}} \text { - a generalized indicator of the j-th subpotential of the i-th region; } \\
\mathrm{n} \text { - the number of subpotentials. }\end{array}$ \\
\hline \multicolumn{2}{|c|}{ 4. Integral indicator of the level of development of economic potential of the region, $\mathrm{I}_{\mathrm{i}}$} \\
\hline$I_{i}=\frac{R_{i}}{R_{r u s}}$ & $\begin{array}{l}\mathrm{R}_{\mathrm{i}}-\text { rating number of the level of development of economic potential of the i-th region; } \\
\mathrm{R}_{\mathrm{rus}}-\text { national average rating number of the level of development of economic potential. }\end{array}$ \\
\hline \multicolumn{2}{|c|}{ 5. The level of capitalization of regional economy, LCi } \\
\hline$L C_{i}=\frac{G R P / c_{i}}{I_{i}}$ & $\begin{array}{l}\text { GRP/ } \mathrm{C}_{\mathrm{i}} \text { - GDP per capita of the region compared to the same national average indicator; } \\
\mathrm{l}_{\mathrm{i}}-\text { an integral indicator of the level of development of the economic potential of the region. }\end{array}$ \\
\hline \multicolumn{2}{|c|}{ 6. The level of capitalization of subpotential of regional economy, $L C_{i j}$} \\
\hline$L C_{i j}=w_{i j} \frac{G R P / c_{i}}{F_{i j}}$ & $\begin{array}{l}\text { Wij - the share of the j-th subpotential in integral indicator of the level of development of } \\
\text { economic potential of the } i \text {-th region; } \\
\text { GRP/c } / c_{i} \text { - GDP per capita of the i-th region compared to the same national average indicator; } \\
F_{i j}-\text { a generalized indicator of the j-th subpotential of the i-th region. }\end{array}$ \\
\hline
\end{tabular}

\section{Findings and Discussion}

The results of the assessment of the level of capitalization of regional economy of Central Black Earth economic region in 2007-2013 are shown in Figure 1.

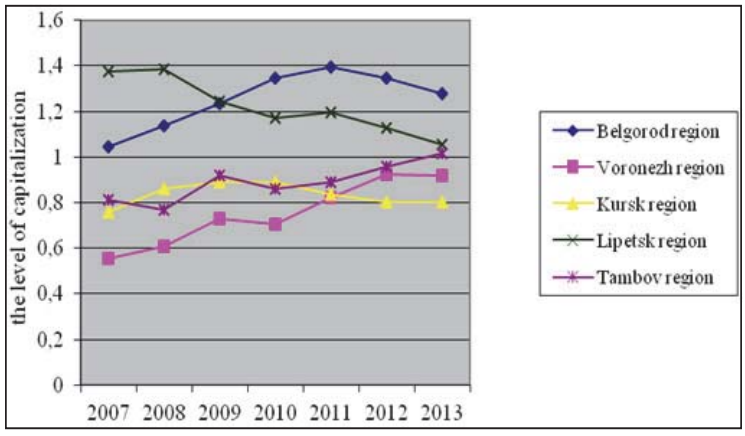

Figure 1. The dynamics of the level of capitalization of the economy of Central Black Earth economic region

The increase in the capitalization of the economic potential is observed in Belgorod (until 2011), Kursk, Voronezh and Tambov regions. Belgorod region demonstrates the highest rates, Voronezh region has the smallest. Lipetsk region is generally characterized by negative growth of capitalization level during the study period.

The complex of territorial factors which reflects an existing economic potential has been analyzed in terms of the 
level of development of individual subpotentials and their impact on the final value of capitalization through direct comparison of the generalized regional development indicators $F_{i j}$ with their national average values equal to 1.

In interpreting the results a map of development and capitalization of economic potential of regions of Central Black Earth economic region with four regional levels of indicators (high, medium, low, extremely low) is made (a fragment of the map for two regions and subpotentials is presented in Table 3).

Table 3. The map of development and capitalization of economic potential of regions of Central Black Earth Economic Region in 2013 (a fragment)

\begin{tabular}{cccc}
\hline Region & Indicator of regional economic potential & Production subpotential & Innovative subpotential \\
\hline \multirow{2}{*}{ Belgorod region } & The level of development & Medium $(0,97)$ & Low $(0,45)$ \\
\cline { 2 - 4 } & The level of capitalization & High $(0,27)$ & Low $(0,13)$ \\
\hline \multirow{2}{*}{ Voronezh region } & The level of development & Low $(0,77)$ & Medium $(0,82)$ \\
\cline { 2 - 4 } & The level of capitalization & Medium $(0,16)$ & Medium $(0,17)$ \\
\hline
\end{tabular}

As a result of analysis we conclude that a common problem for all regions of Central Black Earth Economic Region is the low level of development of natural resources and innovative (with the exception of the Voronezh region) subpotentials and low level of capitalization of financial subpotential (except Belgorod region).

The results of this analysis can be used to propose a set of measures for the regions to stimulate the capitalization of economic potential of the regions, whch includes two destinations: development and growth of capacity of economic potential of the regions and increase of the efficiency of its use in economic circulation. For example, for production subpotential these measures are:

- the creation of enterprises with a high degree of processing of raw materials and waste;

- the adoption of regional laws on public-private partnership focused on joint financing of perspective investment projects;

- encouraging of the modernization of fixed assets of extractive and manufacturing industries by providing tax incentives;

- the creation of concessional lending of investment projects of the modernization of equipment and technologies.

- The set of measures to stimulate the capitalization of innovative subpotential includes:

- the expansion of the network of research centers, the development of innovation infrastructure of universities and research institutions conducting basic and applied research focused on the needs of business;

- the acceleration of the production of innovative products based on the integration of developers, manufacturers and consumers;

- targeted training of specialists in commercialization of research;

- increasing the motivation of employees to the innovative work due to orientation on high incentive systems innovation.

\section{Concluding Remarks}

Thus, using the proposed methodology for the assessment of the level of capitalization of regional economy and the way of visualization of resulting indicators, factors hindering the growth of capitalization and the set of encouraging measures can be identified and differentiated on key aspects that will help to form regional economic development model based on the most efficient use of specific internal factors of the reproductive system of the region.

\section{References}

Brasington, D.M. (2002). Edge versus center: finding common ground in the capitalization debate. Journal of Urban Economics, 52(3), 524-541.

Darmilova, Gh.D. (2007). Capitalization of competitive advantages of local resources in the region is a key strategy of regional development of the North Caucasus. Terra Economicus, 5 (1-3), 86-90.

Dedkova, M.V. (2008). Capitalization and its impact on economic growth (for example of non-public companies). PhD thesis, Moscow.

Gavkalova, N., \& Barka Zine, M. (2012). Synthesized capital and modernization of society. Economics of development, 2(62), 44-50.

Goryachuk, V. F., Pankov, A. V., \& Kozlov, P. P. (2012). Capitalization as a mechanism for increasing the competitiveness of the 
territory. Business Inform, 11, 83-86.

Lyshchikova, Y.V. (2013). Market infrastructure in the context of capitalization of the economy of the region. Modern scientific research and their practical application, vol. J21317. [Online] Available: http://www.sworld.com.ua/e-journal/J21317.pdf. (February 25, 2015).

Malova, T.A. (2007). Capitalization in conditions of the Russian economy: theoretical and practical aspects. LKI.

Molchan, A.S. (2011). Reproduction and capitalization of the economic potential of regional socio-economic systems. Krasnodar.

Nikulina, E.V., Chistnikova, I.V., Orlova, A.V., \& Lyshchikova, Y.V. (2013). The formation of priority directions of social and economic development of the region. World Applied Sciences Journal, 22(5), 608-615.

Nikulina, E.V., Chistnikova, I.V., Orlova, A.V., \& Lyshchikova, Y.V. (2012). The innovative activity of the region: essence, measuring instruments, assessment. Modern scientific research and their practical application, vol. J31211. [Online] Available: http://www.sworld.com.ua/e-journal/J31211.pdf. (February 17, 2015).

Pogodzinski, J.M., \& Sjoquist, D.L. (1993). A note on estimation of capitalization. Public Finance Quarterly, 21(4), 434-448.

Toly, N.J. (2004). Globalization and the capitalization of nature: a political ecology of biodiversity in Mesoamerica. Bulletin of Science, Technology and Society, 24(1), 47-54.

Tsybulsky, V.R., \& Silifonkina, S.V. (2010). The method of estimating the capitalization of the region using the income approach. Regional Economics: theory and practice, 20, 14-19.

Ovchinnikova, O.P., \& Lyshchikova, Y.V. (2011). Capitalization of the assets of the region: the nature, components, problems. Belgorod State University Scientific Bulletin. History Political science Economics Information technologies, 13(108), 44-49. 